\title{
A viagem brasileira de Lorenz Simon
}

\author{
Bruno Romero Ferreira Miranda' \\ Benjamin Nicolaas Teensma²
}

\begin{abstract}
Resumo
Esse texto apresenta o relato de viagem escrito por Lorenz Simon, que esteve no Brasil entre os anos de 1641 e 1654. Além de inserir sua trajetória e seu texto no contexto mais amplo - a migração de mão-de-obra estrangeira para a República Neerlandesa, sua transmigração para os territórios coloniais e o mercado editorial europeu -, oferecemos a tradução integral e comentada do referido panfleto para o português.
\end{abstract}

Palavras-chave: Brasil Holandês; Companhia das Índias Ocidentais; relatos de viagem.

\section{The Brazilian voyage of Lorenz Simon}

\section{Abstract}

This text presents the travel account written by Lorenz Simon, who was in Brazil between the years 1641 and 1654. It aims to insert his trajectory and text within a broader context: the migration of foreign workers to the Dutch Republic, their transmigration to the colonies and the European editorial market. Moreover, it also brings the complete translation into Portuguese of the mentioned pamphlet.

Keywords: Dutch Brazil; West India Company; travel accounts.

\section{El viaje brasileña de Lorenz Simon}

\section{Resumen}

El texto presenta el relato de viaje escrito por Lorenz Simon, quien se encontraba en Brasil entre los años 1641 y 1654. Su objetivo es poner su trayectoria dentro de un contexto más amplio: la migración de trabajadores extranjeros para la República de Holanda, su transmigración para los territorios coloniales y el mercado editorial europeo. Por otra parte, también trae la traducción integral al portugués de ese folleto.

Palabras clave: Brasil Holandés; Compañía de las Indias Occidentales; relatos de viaje.

\section{Le voyage brésilienne de Lorenz Simon}

\section{Résumé}

Ce texte présente le récit de voyage écrit par Lorenz Simon, qui a visité le Brésil entre les années 1641 et 1654. Outre le fait d'introduire sa trajectoire et son texte au sein d'un contexte plus large - la migration d'une main d'œuvre étrangère vers la République Néerlandaise, sa transmigration vers les territoires coloniaux et le marché éditorial européen -, nous proposons une traduction complète et commentée de la dite plaquette en portugais.

Mots-clés: Brésil Hollandais; Compagnie des Indes Occidentales; récits de voyage. 
$\mathrm{E}$ ntre 1930 e 1932, o neerlandês Samuel Pierre l'Honoré Naber (18651936) publicou pela editora Martinus Nijhof uma coletânea intitulada "Descrições de Viagens de funcionários e homens de guerra a serviço das Companhias Neerlandesas das Índias Ocidentais e Orientais 1602-1797" (Naber, 1930/1932). Dois aspectos chamam atenção nessa seleção feita por L'Honoré Naber: os 13 relatos foram produzidos por homens provenientes de localidades do Sacro Império Romano (particularmente dos Estados Alemães) e três deles estiveram no Brasil: Johann Gregor Aldenburgk, entre os anos de 1624 e 1625, Ambrosius Richshoffer, entre 1630 e 1632, e Michael Hemmersam, apenas de passagem pelo Recife no ano de 1645 e cuja narrativa foi concentrada em sua estadia na África Ocidental, entre os anos de 1639 e $1645 .{ }^{3}$

Relatos de militares alemães a serviço da Companhia das Índias Ocidentais (West-Indische Compagnie, ou WIC), como os produzidos por Aldenburgk, Richshoffer e Hemmersam, podem ser encontrados apenas em números bastante reduzidos, especialmente se forem comparados com a quantidade de textos desse tipo observados entre o pessoal contratado pela Companhia Unida das Índias Orientais (Vereenigde Oostindische Compagnie, ou VOC). Alguns motivos podem ser apontados para explicar essa escassez de textos para o lado ociental. A princípio, pode-se dizer que o período de funcionamento ligeiramente mais dilatado da VOC (1602-1799) - em comparação com a WIC, que funcionou entre 1624 e 1792 - e o número superior de recrutados ao longo dos anos sejam fatores preponderantes para o número exíguo de relatos produzidos. ${ }^{4}$ Pesa contra esse argumento, pelo menos para o período anterior à rendição da WIC no Brasil, ocorrida em 1654, o fato de que a maior parte dos recrutados das companhias de comércio neerlandesas era drenada pela WIC. Portanto, seria normal que mais relatos fossem produzidos durante os anos de atuação da WIC no Brasil (1624 a 1654). Entretanto, não foi isso o que se verificou, pois os principais centros de publicação de textos localizados nos Estados Alemães foram afetados pela Guerra dos Trinta Anos (1618-1648).

A florescente cultura livresca existente na região sofreu um duro golpe com o conflito. Grandes editoras em Augsburg, Nuremberg e Frankfurt sofreram danos enormes com a morte e migração de muitos leitores. O impacto da guerra, nesse aspecto, pode ser exemplificado com números: entre os anos de

\footnotetext{
${ }^{3}$ Apenas os relatos de Aldenburgk (datado de Grüner, 1627) e de Richshoffer (datado de Estrasburgo, 1677) foram traduzidos para o português. O ourives e soldado proveniente de Nuremberg, Michael Hemmersam, que esteve em Elmina por cinco anos, ainda não teve seu texto (datado de Nuremberg, 1663) traduzido para o português. Para as versões em língua portuguesa das narrativas de Aldenburgk e de Richshoffer, ver Aldenburgk (1961); Richshoffer (1977). Os relatos de Aldenburgk e de Richshoffer não foram os únicos textos sobre o Brasil publicados por L'Honoré Naber, que também editou, entre outros, os textos de Caspar Barlaeus, Hendrik Haecxs e Johannes de Laet. Tanto a obra de Barlaeus, quanto a de Johannes de Laet, dispensam apresentações. O diário de Haecxs, conselheiro do Alto Governo do Brasil entre 1645 e 1654 , também conta com uma versão portuguesa. Publicado nos Anais da Biblioteca Nacional em 1950, o diário oferece uma visão dos anos finais da Companhia das Índias Ocidentais no Brasil. Ver Haecx (1950).

${ }^{4} U \mathrm{~m}$ bom exemplo pode ser observado no trabalho de Roelof van Gelder, Het Oost-Indisch avontuur, que traz informações sobre 47 funcionários da VOC - muitos dos quais militares - e suas narrativas de viagem. Ver: Gelder (1997). Em obra posterior, Van Gelder, juntamente com a pesquisadora neerlandesa Vibeke Roeper, levantaram cerca de 100 relatos de gente a serviço da VOC. Ver Roeper; Gelder (2002).
} 
1610 e 1619, os editores dessas localidades colocavam no mercado uma média anual de 1.587 livros. Entre 1632 e 1641, em pleno conflito, o número caiu para 660. Após a assinatura dos Tratados de Münster e Osnabrück (a chamada Paz de Vestfália), em 1648, a quantidade de publicações lançadas aumentou gradualmente, mas seria apenas no século XVIII que o mercado do livro retomaria os índices do período que antecede a guerra (Gelder, 1997, p. 96-97). Nessa altura, o interesse do público alemão e neerlandês nos relatos sobre o Brasil já havia fenecido. Por outro lado, também é necessário levar em conta a falta de gente escolada entre os recrutados, embora estudos específicos sobre o assunto ainda sejam necessários.

É igualmente interessante, no que se refere à publicação de relatos de viagem sobre as Índias, que as narrativas tenham sido escritas majoritariamente por gente oriunda dos Estados Alemães. Embora muitos dos homens a serviço da WIC e da VOC fossem provenientes dessas localidades, usalmente não compunham mais do que $30 \%$ do pessoal militar na primeira companhia. De acordo com Bruno Miranda, uma análise detalhada de uma amostragem de 4.303 recrutados pela WIC para servir no Brasil, entre os anos de 1632 e 1654, aponta que 26,3\% desse povo era originário dos Estados Alemães (Miranda, 2014, p. 56). Em outras companhias de comércio neerlandesas ou em outras localidades sob domínio da WIC ou da VOC, pessoas dos Estados Alemães também compunham a parte majoritária dos recrutados estrangeiros. No século XVII, nos Novos Países Baixos, de uma pequena amostra de 304 soldados, o percentual de alemães era de 35\% (Jacobs, 2006, p. 135). Na VOC, pode-se dizer que $40 \%$ dos marinheiros e $60 \%$ dos soldados eram estrangeiros, a maioria proveniente dos Estados Alemães. Em 1770, o número de estrangeiros subiria para 80\%, embora seja desconhecido o percentual de alemães (Gaastra, 2003, p. 81-82). Nos séculos XVII e XVIII, na Directie van Suriname - chamada inicialmente de Sociëteit van Suriname -, companhia privada neerlandesa que colonizou o Suriname e da qual a WIC deteve controle parcial, a gente dos Estados Alemães era preponderante entre os oficiais comissionados e soldados ordinários (Lohnstein, 1984, p. 86, 94-95).

Mas por que tão poucos relatos de neerlandeses são encontrados? Uma resposta plausível para o pequeno número de textos produzidos por neerlandeses pode estar atrelada ao fato de que os recrutados oriundos dos Países Baixos eram mais suscetíveis à censura, pois tanto a WIC quanto a VOC tinham regras específicas - instituídas em cartas-artigos - para evitar que mapas e textos a respeito do comércio e da guerra fossem produzidos, sob pena de multa pecuniária. Excetuava-se, é claro, o conteúdo produzido para os diretores das companhias ou às respectivas câmaras ${ }^{5}$. O objetivo era evitar que qualquer

${ }^{5} \mathrm{~A}$ organização administrativa da Companhia das Índias Ocidentais era descentralizada em cinco câmaras, algumas delas representando os interesses de várias cidades. A administração geral era formada por um colegiado de diretores - num total de 19 -, indicados por essas câmaras. Um deles era apontado pelos Estados Gerais, o parlamento da República das Províncias Unidas que autorizou o funcionamento da WIC. Para mais informações ver Heijer (2005). 
informação sensível pudesse chegar às mãos de competidores ${ }^{6}$. De acordo com Charles Ralph Boxer, deve ainda ser levado em consideração que havia entre as classes média e alta neerlandesas, como será visto adiante, resistência em aceitar trabalhos no ultramar (Boxer, 1977, p. 51). É razoável supor que entre esses elementos estivesse a maioria instruída, o que fez rarear ainda mais os escritos produzidos pelos recrutados.

A despeito da diminuta quantidade de relatos de gente que circulou no Brasil, alguns textos continuam inéditos ou sem traduções para o público brasileiro e neerlandês. Dois exemplos são os diários dos militares Johann Paul Augspurger e Peter Hansen Hajstrup.

\author{
É igualmente interessante, no que se refere à publicação \\ de relatos de viagem sobre as Índias, que as narrativas \\ tenham sido escritas majoritariamente por gente \\ oriunda dos Estados Alemães
}

Augspurger foi contratado como Commandeur de tropas que seguiam para o Brasil pela Companhia das Índias Ocidentais, câmara de Amsterdã, em outubro de 1640, tendo anteriormente trabalhado para neerlandeses e franceses. Em novembro de 1640, ele partiu de Texel para o Brasil, local onde chegou em fevereiro de 1641. O Brasil não seria o único local de destino, pois Augspurger rumaria para África ainda em 1641, na expedição para conquistar São Tomé e Angola comandada pelo almirante Cornelis Cornelisz Jol e pelo tenente-coronel James Henderson. Augspurger voltou para o Brasil em 1642 e, de lá, retornou para as Províncias Unidas. A história foi narrada por ele em um diário publicado em Schleusingen, no ano de 1644, na oficina do impressor Johann Michael Schalln?

\footnotetext{
${ }^{6}$ Ver Gelder (1997, p. 14, 81-82); Miranda (2014, p. 196-197). Diz o artigo CXVI de uma carta-artigo publicada em 1640: "A ninguém navegando pela Companhia, independente do posto, será permitido escrever uma carta a qualquer amigo ou a conhecidos, ou a alguém qualquer, mesmo a diretores em particular, sobre o comércio, guerra, comportamento de algum funcionário da Companhia nas Índias Ocidentais. Só é possível escrever a alguém da Companhia, aos diretores ou às respectivas Câmaras para onde estão navegando, sob pena de três meses de salário aos que forem pegos [fazendo o contrário]". Articul-Brief. Beraemt over het Scheeps ende Crijgs Volck. Ten Dienste van de Geoctroyeerde West-Indische Compagnie in Brasyl, Guinea, etc, Groningen, Sas, 1640. Tradução livre.

${ }^{7}$ Agradecemos ao historiador neerlandês Roelof van Gelder pela indicação do diário de Johann Paul Augspurger. Uma das poucas menções sobre Augspurger pode ser encontrada no trabalho da etnóloga alemã Beatrix Heintze, "Exploradores Alemães em Angola (1611-1945)". Além de compor uma pequena biografia a respeito do militar, B. Heintze transcreve o trecho no qual ele narra sua ida à África. O texto foi traduzido para o português por Rita Coelho-Brande e Marina Santos. Ver Heintze (2010). O nome de Augspurger e o título de seu diário também foram mencionados por Enrico Schaeffer em um artigo sobre Albert Eckhout publicado em 1968 nos Anais do Museu Histórico Nacional. O diário foi igualmente citado em outras publicações, embora seu texto - na íntegra - continue desconhecido do grande público. Para o diário, que pode ser encontrado na biblioteca universitária de Dresden, ver Augspurger (1644).
} 
Já Peter Hansen, filho de um camponês da pequena vila de Hajstrup no Sul da Jutlândia (Dinamarca), saiu de casa em busca de melhores alternativas de vida. Migrou para Copenhagen, onde trabalhou como ajudante de secretário na padaria do Real Armazém dos Víveres do monarca da Dinamarca. Após desentendimentos, Peter Hansen pediu demissão e seguiu para Amsterdã à procura de um novo emprego, engajando-se como soldado na Companhia das Índias Ocidentais. Ele acabou sendo enviado para o Brasil, onde chegou em fins de 1644. Peter Hansen participou das tentativas da Companhia das Índias Ocidentais de suprimir a revolta dos moradores iniciada em meados de 1645 e tomou parte nas batalhas de Tabocas (1645), Casa Forte (1645) e Guararapes (1648). Posteriormente, ele esteve estacionado no Rio Grande, onde ficou até a rendição da Companhia, em 1654. Suas experiências no Brasil foram registradas em um diário manuscrito iniciado em 1662, que está depositado no arquivo provincial de Schleswig-Holstein, na Alemanha. É um fragmento de um diário ainda mais extenso, que narra sua vida entre os anos de 1624 e $1672^{8}$.

Além dos textos supracitados, um outro texto encontra-se nesse escasso nicho: um relato de viagem - curiosamente publicado na forma de panfleto em alemão do século XVII, sem indicação do impressor, de oito páginas e com uma gravura em preto e branco (ca. $22,5 \times 7 \mathrm{~cm}$ ), sob o título "Viagem brasileira de um soldado alemão na América. Coisas que lhe aconteceram, como também os perigos de corpo e de vida que nela passou. Seu nome: "Lorenz Simon da Saxônia, de Bernsdorf na Turíngia. Impresso no ano de 1677" ("Prasilische Reise von einem Teutschen Soldaten in America, wie es ihm allda ergangen auch Leib und Lebens-Gefahr allda ausstehen müssen Nahmens Lorenz Simon aus Sachsen von Bernsdorff in Thüring. Gedruck't im Jahr 1677"). O impresso de Lorenz Simon pode ser encontrado na British Library, em Londres, sob o número 10480aaa7. Outra cópia está depositada na biblioteca universitária de Dresden (Sächsiche Landesbibliothek - Staats-und Universitätsbibliothek Dresden), sob o número NUC-547.NS0562794.

Para não dizer que o texto em questão é totalmente desconhecido, José Antônio Gonsalves de Mello, em Tempo dos Flamengos. Influência da ocupação holandesa na vida e cultura do norte do Brasil, fez uma das poucas referências existentes a Lorenz Simon (Mello, 2002, p. 37). Na mesma passagem do prefácio em que citou o nome de Simon, Gonsalves de Mello mencionou o nome de vários outros viajantes que deixaram impressões sobre suas estadias no Brasil durante qualquer momento entre 1630 e 1654, entre eles, Nicolaas

${ }^{8}$ Em 1995, o texto completo desse diário foi transcrito e publicado integralmente em alemão do século XVII por Frank Ibold, Jens Jäger e Detlev Kraack (1995). A história de Peter Hansen também foi citada nos artigos: Kraack (1996); Groesen (2010); Jacobs (2006). Miranda (2014), em seu livro Gente de guerra também falou da trajetória de Peter Hansen no Brasil. O diário de Peter Hansen foi traduzido para o português por B. N. Teensma e está em processo de preparação por Bruno Romero Ferreira Miranda e Lucia Furquim Werneck Xavier para publicação. 
de Graaff, Cuthbert Pudsey e Zacharias Wagener. Os dois últimos tiveram seus relatos traduzidos para o português em publicações recentes ${ }^{9}$ (Pudsey, 2000; Wagener, 1997).

A única informação mais detalhada sobre Lorenz Simon é restrita a um pequeno artigo feito por Alfredo de Carvalho, conhecido por suas traduções para a Revista do Instituto Arqueológico, Histórico e Geográfico Pernambucano ${ }^{10}$. Esse texto, de 1904, intitulado "A Viagem Brasílica de Lorenz Simon" - que empresta o título a este artigo - é praticamente uma tradução parcial do texto deixado pelo militar, que foi encontrado por Manuel de Oliveira Lima no Museu Britânico.

Para não dizer que o texto em questão é totalmente
desconhecido, José Antônio Gonsalves de Mello, em
Tempo dos Flamengos, fez uma das poucas referências
existentes a Lorenz Simon

Segundo Carvalho, a primeira referência conhecida foi feita pelo bibliógrafo português, Manoel Bernardes Branco, que havia encontrado o texto de Simon num catálogo do livreiro parisiense Chassonery (Carvalho, 1904, p. 641).

A tradução do panfleto de Simon feita por Alfredo de Carvalho foi seletiva, uma vez que ele achava que o texto - em sentença típica dos historiadores do século XIX - tinha "apenas o interesse de uma curiosidade bibliográfica, sendo nulo o seu valor documentário" (Carvalho, 1904, p. 644). O autor, utilizando-se do texto, elaborou uma pequena biografia de Simon. Nascido em Bernsdorf, em data desconhecida, Lorenz Simon deixou a casa dos pais em agosto de 1633. Ainda muito jovem, partiu para Eisleben - onde frequentou a escola por dois anos - e depois seguiu para Quedlinburg, ambas cidades da Saxônia. Trabalhou por mais dois anos como aprendiz de livreiro em Braunschweig, serviu como soldado da cavalaria sueca - participando da Guerra dos Trinta Anos e passando por localidades do Sacro Império e também da Polônia - e trabalhou com um comerciante em Danzig. De lá, seguiu em um veleiro para a Holanda, em fins de 1639. Trabalhou na cidade de Leiden até fins de 1640, quando se alistou no escritório da Companhia das Índias Ocidentais em Delft para seguir ao Brasil, onde chegou no mês de março de 1641. Ele serviu por algum tempo

\footnotetext{
${ }^{9} \mathrm{O}$ cirurgião neerlandês Nicolaas de Graaff, que esteve por muitos anos a serviço da VOC e que também trabalhou para os Estados Gerais da República das Províncias Unidas dos Países Baixos, esteve no Brasil entre maio de 1650 e fins de 1653. Seu relato de viagens empreendidas no ultramar foi publicado em 1701 sob o título de Reisen van Nicolaus de Graaff na de vier gedeeltens des werelds, als Asia, Africa, America, en Europa. Em 1908, Alfredo de Carvalho traduziu e publicou parte do texto relativo a sua ida ao Brasil. Ver Carvalho (1908, p. 78-83).

${ }^{10}$ Carvalho era versado em francês, alemão, inglês, neerlandês, italiano e espanhol, o que o habilitou a traduzir muitas obras importantes para a história do Brasil colonial. Produziu mais de 200 trabalhos publicados como livros ou em periódicos. Ver Carvalho (2011, p. 367).
} 
no iate Hazewint (Galgo) e ficou no Recife até 1649, quando tomou parte na segunda batalha dos Guararapes. No confronto, ele acabou sendo feito prisioneiro. Simon conseguiu escapar e retornar para o Recife, onde continuou a serviço da WIC até a rendição ocorrida em 1654. Ele chega aos Países Baixos em agosto do mesmo ano ${ }^{11}$ (Carvalho, 1904, p. 642-644).

Não foi encontrado qualquer registro da passagem de Lorenz Simon pelo Brasil nos papéis da WIC e ele mesmo não oferece muitos detalhes de sua estadia, exceto pela ênfase no episódio da fuga do cativeiro, talvez uma influência do editor - caso tenha existido um - para atrair público para seu panfleto. De acordo com Michiel van Groesen, acrescentar uma certa dose de ficção, aliás, era uma prática muito comum na indústria livreira do período (Groesen, 2010, p. 47). No geral, Simon compôs um texto muito simples e seco, preponderantemente enumerativo e sem abordar a fundo qualquer um dos vários episódios os quais ele deve ter presenciado nos seus quase 14 anos de estadia no Brasil. Porém, tal composição é típica do período, no qual é corrente perceber certo laconismo, mesmo na correspondência privada, e é por isso que até mesmo os perigos de morte eram descritos em um estilo factual. Pode-se, contudo, observar que existe um forte componente de autobiografia em seu texto e, apesar das poucas linhas, descreveu um pouco da sua juventude, do caminho que percorreu até empreender a viagem ao Brasil e até externou um pouco dos seus sentimentos, por vezes acompanhados de termos religiosos. Esse aspecto também é observável em vários relatos de viajantes coevos, que compuseram um gênero chamado de relato de viagem autobiográfico (Roeper; Gelder, 2002, p. 18-19; Gelder, 1997, p. 78).

É possível, todavia, refletir mais sobre o texto de Simon e inserir sua viagem ao Brasil dentro de um contexto mais amplo. O impresso, tais quais os relatos de viagem supracitados, fazia parte da enxurrada de escritos sobre o novo mundo publicados no mercado editorial europeu. Ainda que não seja possível afirmar que os textos escritos em alemão penetrassem nos Países Baixos, essa região havia se transformado em um centro de comércio de livros. Por volta do ano de 1500, cerca de 20 tipografias estavam em plena atividade nessa região onde se publicava desde meados do século XV. Na Antuérpia, entre os anos de 1500 e de 1540, pelo menos 66 oficinas publicaram títulos em neerlandês, latim, francês, espanhol e inglês. Os textos certamente encontravam leitores, pois na Antuérpia do século XVI, $50 \%$ dos homens podiam ler. Tal nível é semelhante aos da cidade de Amsterdã no começo do século XVII. Embora não seja possível generalizar,

\footnotetext{
"Prasilische Reise von einem Teutschen Soldaten in America, wie es ihm allda ergangen auch Leib und Lebens-Gefahr allda ausstehen müssen Nahmens Lorenz Simon aus Sachsen von Bernsdorff in Thüring. Gedruck't im Jahr 1677. Uma pequena cronologia da trajetória de Lorenz Simon pode ser feita a partir do impresso: 08/08/1633 - Deixa a casa paterna; 1633 a 1635 - Frequenta uma escola em Eisleben; 1635 a 1637 - Trabalha como aprendiz de livreiro em Braunschweig; 1637 a 30/11/1639 - Serve na cavalaria do exército sueco. Trabalha, provavelmente por quatro meses e meio, com um comerciante em Danzig e segue em uma embarcação para a Holanda; 30/11/1639 a 12/12/1640 - Chega a Amsterdã, trabalha em uma loja da cidade de Leiden e se alista no escritório da WIC na cidade de Delft; 21/12/1640 até março de 1641 - Sai de Roterdã e chega ao Recife; Março de 1641 a 19/02/1649 - Serve em mar e em terra até ser feito prisioneiro na Segunda Batalha dos Guararapes; 08/08/1649 - Escapa do cativeiro no Cabo de Santo Agostinho e retorna ao Recife, onde segue trabalhando para a WIC; 1654 a 10/08/1654 - Deixa o Brasil e chega a Vlissingen, nas Províncias Unidas.
} 
muitos neerlandeses podiam ler os muitos livros - às vezes, em idiomas não nativos - que circulavam em uma vibrante cultura tipográfica (Schmidt, 2001, p. 8-10).

Caso não tivesse público para seu texto nas Províncias Unidas, Simon o teria nos Estados Alemães. Seu texto, aliás, foi certamente escrito para esse mercado, onde uma grande quantidade de relatos sobre a Ásia e América do Sul foi publicada nos séculos XVII e XVIII. A data de publicação, 1677, pode ser explicada pela retomada do mercado editorial nos Estados Alemães, que voltou a crescer na década de 60 do século XVII, depois de ter sido duramente afetado pela Guerra dos Trinta Anos. A década, aliás, foi marcada por uma moda na publicação de textos sobre a Ásia, sobretudo traduções de relatos em neerlandês (Gelder, 1997, p. 97). Apesar da perda de interesse pelo Brasil nos Países Baixos e nos Estados Alemães, não é fortuito que outros dois relatos de militares que passaram pela região, como os escritos por Michael Hemmersam e Ambrosius Richshoffer - publicados respectivamente em 1663 e 1677 -, também tenham sido impressos durante essa nova fase do mercado editorial alemão. É provável que Simon tenha seguido essa tendência. Em relação ao formato de publicação escolhido, talvez tenha sido decorrência da ausência de um editor. Isso faz sentido se pensarmos que Simon pode ter custeado a impressão de seu relato. $O$ valor de impressão de um panfleto certamente era menor do que seria na forma de livro. Em relação aos fatores que o levaram a publicar seu relato, devem ter pesado, além da vontade de contar suas experiências, seu desejo de obter alguma vantagem, haja vista que Simon dedicou a obra a Johann Georg II, príncipe eleitor da Saxônia ${ }^{12}$.

Ainda a respeito da grande circulação de textos sobre terras distantes, vale a pena mencionar o que disse um contemporâneo de Lorenz Simon, o compilador Erasmus Francisci (1627-1654), autor de uma monumental enciclopédia - de 1.762 páginas - intitulada Ost- und West-Indischer wie auch Sinesische Lust und Stats- Garten (Jardins recreativos privados e públicos da China e das Índias Ocidentais e Orientais), de 1668. Francisci dizia que já haviam sido publicados tantos livros sobre a Ásia que era melhor ir às Îndias do que ler todos eles. A opinião parece ser partilhada por um ex-soldado da VOC, Ernst Christoph Barchewitz, que publicou Allerneueste und wahrhaffte Ost-Indianische ReiseBeschreibung (Novíssimo e verdadeiro itinerário às Índias Orientais) - cuja primeira impressão foi feita em 1730. Barchwitz menciona que as Índias Orientais já haviam sido tão bem descritas por alemães que a região já era tão conhecida como a própria Alemanha. Pode parecer exagero dos autores, mas entre os anos de 1600 e 1800, estima-se que foram lançados de 500 a 600 títulos sobre a Ásia, o que dá uma média de 2 a 3 livros por ano (Gelder, 1997, p. 75-76; 97-98). Se incluídas na contagem as Índias Ocidentais, o número aumentará consideravelmente.

Outro aspecto também pode ser mencionado ao se observar a jornada feita por Lorenz Simon. Ela está inserida em uma ampla corrente migratória direcionada aos Países Baixos, especificamente na área que compreendia a República

${ }^{12}$ De acordo com Roelof van Gelder, também existe um propósito específico em se fazer uma dedicatória a alguém importante: proteger o autor das críticas e oferecer uma espécie de garantia de veracidade do relato. Ver Gelder (1997, p. 87). 
das Províncias Unidas dos Países Baixos. Tal fluxo de pessoas não foi gerado por acaso e também não foi limitado a um curto período de tempo. Calcula-se que, entre os anos de 1600 e de 1800, mais de dois milhões de imigrantes foram para regiões centrais no Oeste da República, com o objetivo de residir, trabalhar temporariamente ou servir em suas tropas, navios e colônias (Lucassen, 1994, p. 175). Nesse período, entre as muitas regiões da Europa Ocidental, a área da República era vista como a mais atrativa por conta da sua prosperidade econômica, melhores salários e maior liberdade religiosa. Ainda que tais vantagens devam ser relativizadas, uma vez que a República não era tolerante com todas as ideias dissidentes e não era um paraíso para todos os que viviam dentro de suas fronteiras, a região não sofreu de maneira drástica os efeitos de conflitos travados em áreas próximas, isto é, a Guerra dos Trinta Anos e a Guerra dos Oitenta Anos (1568-1648) (Lucassen, 1994, p. 153). Ademais, a

\section{O impresso, tais quais os relatos de viagem supracitados, fazia parte da enxurrada de escritos sobre o novo mundo publicados no mercado editorial europeu}

prosperidade da República contrastava, apesar da péssima situação dos trabalhadores, com a miséria e o desemprego das terras vizinhas (Boxer, 1977, p. 58; Schama, 1992, p. 171-172).

Dentre os migrantes masculinos estabelecidos na República, boa parte foi direcionada para compor as fileiras do exército europeu e colonial, continuamente dependente do componente estrangeiro para fortalecer seus efetivos. Como esses estrangeiros foram redirecionados para trabalhar nas colônias, eles podem ser chamados de transmigrantes, uma vez que a República figurou apenas como local de trânsito ou estabelecimento temporário (Parker, 1996, p. 49; Lucassen, 1994, p. 181-182; Vries, 1997, p. 72-78). Além da composição das tropas na luta contra os espanhóis em suas fronteiras, a República carecia do elemento estrangeiro para os trabalhos agrícolas e industriais na Europa, para o arranjo das tripulações dos navios mercantes e das companhias de comércio de além-mar e dos agrupamentos militares nas colônias. De fato, a manutenção dos interesses comerciais no império marítimo neerlandês requeria uma força de trabalho tão grande que a República não podia depender apenas do crescimento natural da sua própria população, que no zênite de seu desenvolvimento econômico foi estimada em cerca de 1.950.000 (Lucassen, 1994, p. 165-166; Israel, 1995, p. 620). Somente o mercado de trabalho masculino nas regiões centrais da República dependia em $50 \%$ de pessoas nascidas fora dessas áreas (Lucassen, 1994, p. 176).

No caso da composição dos efetivos marítimos, militares e operacionais do ultramar, havia ainda uma relutância das classes média e alta neerlandesas em aceitar trabalho nessas companhias. Essa falta de motivação está 
relacionada aos riscos da viagem às Índias e aos perigos da vida nos trópicos, além das possibilidades de obtenção de emprego na República. Isso ajuda a explicar porque ambas as companhias empregavam grandes proporções de estrangeiros, inclusive gente sem qualquer experiência militar, algo muito comum nos exércitos europeus do período (Miranda, 2014, p. 390-391; Boxer, 1977 , p. 5). Foi por conta dessa necessidade que Lorenz Simon conseguiu trabalho na WIC.

Não é uma surpresa ressaltar que as pessoas vindas dos Estados Alemães, como Simon, dentro da área do Sacro Império Romano, compusessem o maior grupo de estrangeiros a serviço da WIC. O declínio econômico dos Estados Alemães durante a primeira metade do século XVII impulsionou a movimentação de muitos alemães para a República. Ademais, as destruições promovidas pela Guerra dos Trinta Anos, especialmente nas regiões de Württemberg (Sudoeste), nas vizinhanças de Nuremberg e em partes da Saxônia, foram determinantes no deslocamento de pessoas. Não foi casual que Simon, já órfão, tenha dito que a péssima situação de sua "pátria" o impelira a deixar a livraria onde trabalhava para seguir com o exército sueco. Perambulou pela Europa do Norte até seguir para as Províncias Unidas. Tal tipo de deslocamento fizera futuramente com que nada menos do que $5 \%$ da população neerlandesa dos séculos XVII e XVIII, segundo estimativas, tenha nascido nos Estados Alemães. As regiões mais próximas, entre as cidades e os estados de Schleswig-Holstein, Hamburgo (Baixa Saxônia), Bremen, Ostfriesland (Noroeste da Baixa Saxônia) e Oldenburg (Baixa Saxônia), foram as que mais contribuíram com migrantes. No século seguinte, as origens dos migrantes foram predominantes da Baixa Saxônia ${ }^{13}$ (Gelder, 1997, p. 54; 64-65). Lorenz Simon, antecipando uma tendência, não fugiu à regra: era proveniente da Saxônia.

Ao contrário da tradução feita por Alfredo de Carvalho, que selecionou apenas os trechos que julgou importante, apresentamos uma tradução integral do texto de Lorenz Simon. Ademais, inserimos notas que contextualizam os eventos narrados.

\footnotetext{
${ }^{13}$ É importante dizer que o declínio parece ter sido anterior ao início da Guerra dos Trinta Anos, em 1618 Tem relação com a política fiscal de Carlos V e Felipe II, com a perda de espaço das cidades alemãs da Liga Hanseática para a Suécia, no Báltico, e com o surgimento de potências comerciais como a Inglaterra, França e a própria República, que acarretaram o desvio do comércio da região. Há aliás, um antigo e longo debate entre os pesquisadores da Guerra dos Trinta Anos a respeito do declínio econômico anterior à guerra ou posterior à ela. Theodor Rabb escreveu um artigo para mostrar os posicionamentos dos historiadores da chamada "escola desastrosa" e dos que advogavam um "declínio anterior" ao ano de 1618. Ele afirma que não é possível falar de um declínio econômico uniforme em uma vasta região. O certo é que a guerra levou grande destruição, tendo agravado as condições de áreas em declínio ou levado à crise áreas que não tivessem problemas econômicos. Para mais informações, ver Rabb, 1962; Friedrichs (2007, p. 191). A respeito da Liga Hanseática, seu declínio já era aparente desde o começo do século XVI, embora as cidades participantes continuassem a se desenvolver. A organização da Hansa não Ihes era mais útil e a liga terminou desaparecendo na terceira década do século XVII. Ela foi substituída por uma limitada aliança entre as cidades de Lübeck, Hamburgo e Bremen. Ver Mauro (1990, p. 256-257). Sobre os problemas financeiros dos governos de Carlos V e Felipe II, ver Lynch (2005, p. 464-473, 655-701).
} 


\section{Tradução do panfleto}

[Folha 1]

Viagem brasileira de um soldado alemão na América ${ }^{14}$.

Coisas que lhe aconteceram, como também os perigos de corpo e de vida que nela passou.

Seu nome: Lorenz Simon da Saxônia, de Bernsdorf na Turíngia ${ }^{15}$.

Impresso no ano de 1677.

\section{[Folha 2]}

Ao Sereníssimo e Ilustríssimo Príncipe e Senhor,

o Senhor Johann Georg, o Segundo,

Duque da Saxônia, Jülich, Cleve e Berg,

Marechal Herdeiro e Príncipe Eleitor do Sacro Império Romano,

Landgrave da Turíngia,

Margrave de Meissen e da Baixa e Alta Lausácia,

Burgrave de Magdeburgo,

Conde da Marca e de Ravensburgo,

Senhor em Ravensburgo ${ }^{16}$.

Meu Clementíssimo Príncipe Eleitor e Senhor:

\section{[Folha 3]}

História verdadeira ou relato breve da viagem de um soldado alemão à América, na costa do Brasil entre Pernambuco e Cabo de Santo Agostinho. A 8 de agosto do ano de 1633, depois da morte de meu pai, ocorrida no mês de março, saí menino moço da minha terra; primeiro a Eisleben e depois a Quedlinburg à casa do irmão da minha mãe ${ }^{17}$. Lá visitei a escola durante dois anos. Depois fui parar em Braunschweig como aprendiz de livreiro ${ }^{18}$. Passei dois anos naquela livraria. Ao fim desses dois anos, prometeram me contratar

\footnotetext{
${ }^{14}$ Tradução feita por B. N. Teensma. Notas por B. R. Ferreira Miranda.

${ }^{15}$ É difícil dizer qual é a Bernsdorf mencionada por Lorenz Simon. Tanto a Saxônia quanto a Turíngia possuem cidades ou distritos com essa denominação. Por conta da dedicatória feita pelo autor ao eleitor da Saxônia, Johann Georg II, pode-se supor que ele se refira a uma Bernsdorf situada na Saxônia. Todas as observações sobre nomes de cidades, regiões etc., sobretudo as menos conhecidas ou cuja grafia no panfleto (diferenciada pelo itálico) difere do nome atual, foram feitas com o auxílio dos livros Compact History of the World, editado por Geoffrey Parker e Atlas of the World, ambos publicados pelo jornal inglês The Times.

${ }^{16}$ Johann Georg II (1631-1680) foi príncipe eleitor da Saxônia entre os anos de 1656 e 1680. Para mais informações, ver: Allgemeine Deutsche Biographie. "Landgrave" e "Margrave" são títulos nobiliárquicos utilizados em regiões do Sacro Império. Já "burgrave" era um termo utilizado - desde a Idade Média - para o comandante militar de cidade alemã. É equivalente a castelão, ou seja, um governador de um castelo ou cidade fortificada.

${ }^{17}$ Eiszleben, ou Eisleben, é uma cidade localizada na Saxônia. É a cidade de origem de Martinho Lutero (14831546). Quedlinburg - ou Quetlinburg - também está localizada na Saxônia.

${ }^{18}$ No original, Buchführer. Braunschweig é uma cidade localizada na Baixa Saxônia, ao norte das montanhas Harz. Às vezes, é aportuguesado para Brunsvique.
} 
por mais oito anos e conseguir uma certidão de nascimento ${ }^{19}$. Mas não tive ajuda ou meios para tal. Como naquela época minha pátria passou por péssimas situações, segui com um capitão e alguns cavaleiros suecos a Leipzig, e depois a Wittenberge, Berlim, Frankfurt sobre o Óder,

\section{[Folha 4]}

Estetino na Pomerânia, Poznań na Polônia, e finalmente em Gdańsk com um comerciante. Nessa cidade, passei 18 semanas em uma estalagem de nome O Cisne Branco ${ }^{20}$. Saindo depois de Gdańsk, viajei como passageiro em um navio veleiro à Holanda. Passamos quatro semanas no Sund para aguardar toda a frota de navios oriundos da Prússia, Suécia, Livônia e de todas as cidades marítimas ao redor do Mar Báltico ${ }^{21}$. Depois, passamos pelo Sund em um grupo de mais de 100 navios e logo depois de termos passado o Castelo de Cronenburg e entrarmos no Mar do Norte, 25 navios de guerra holandeses aproximaram-se para comboiar-nos ${ }^{22}$. Foi um prazer navegar em semelhante frota, mas tal prazer não durou muito. Em poucos dias, entramos em uma tempestade com trovoadas tão furiosas que não sabíamos onde os demais navios tinham ficado. A tempestade durou vários dias, nos quais navegamos noites e dias, na graça de Deus e sem velas, para onde quer que o vento e a tempestade fossem servidos dirigir-nos. Vários navios foram propulsionados aos escolhos e rocas da costa norueguesa.

\section{[Folha 5]}

Tendo encontrado alguns navios da nossa frota, içaram as velas para continuar a viagem, mas logo depois foram separados outra vez pelos ventos da tempestade. Muitos navios dessa frota perderam-se com sua gente e carga. Os piratas de Dunquerque também apoderaram-se de muitíssimos navios dessa frota. No último dia de novembro do ano de 1639, chegamos sãos e salvos com nosso navio e tripulantes em Amsterdã. Segui viajando à Leiden, onde estive tra- balhando algum tempo com um negociante da Rua de Haarlem, na loja No Mundo da $\mathrm{Cruz}^{23}$.

Depois, tomei uma decisão e no dia 12 de dezembro de 1640, alistei-me na Holanda, na Casa das Índias Ocidentais da cidade de Delft, como soldado para

\footnotetext{
${ }^{19}$ No original, Simon utiliza o termo Geburts-Brieff, carta ou certidão de nascimento. Sabe-se que o recebimento de uma certidão de nascimento era uma exigência feita pelas corporações de ofício alemãs para autorizar qualquer forasteiro a exercer um ofício numa cidade.

${ }^{20}$ Wittenberg - ou Wittenberge - está localizada no Rio Elba, um pouco acima de Berlim. "Estetino" corresponde a Szczecin em polonês e Stettin em alemão, conforme a grafia do panfleto. Já "Poznań" foi grafada como "Bosen" e "Gdańsk" como "Danzig". A estalagem está nomeada como "Der weisse Schwahn".

${ }^{21}$ Grafada como "Sunde", Sund fica numa ilha do Mar Báltico (Åland), entre a Finlândia e a Suécia. Lieffland ou Livônia, é uma área na costa oriental do Mar Báltico, atualmente correspondente à Letônia e Estônia.

${ }^{22}$ No original, Castel Cronenburg. O castelo de Cronenburg - ou Kronborg, em dinamarquês - fica no estreito de Öresund, entre a Dinamarca e a Suécia.

${ }^{23}$ Haarlammer Strassen - ou Haarlemmerstraat, em neerlandês - é atualmente a principal rua de comércio da cidade de Leiden. A loja "No Mundo da Cruz" foi grafada como Welt voll Creutz.
} 
o Brasil ${ }^{24}$. No dia 21 desse mês, saímos ao mar pelo rio Mosa, passando o nosso navio, chamado Fortuna, de Roterdã, pelo Canal da Mancha nos dias 28 e 29. No 25 de janeiro do ano de 1641, estivemos na altura do Estreito de Gilbratar,

\section{[Folha 6]}

onde entram todos os navios à Gênova, Livorno, Nápoles, Sicília, Malta, Iráclio e todas as cidades portuárias ao redor $^{25}$. No estreito à mão esquerda, jaz a Espanha, e à direita, em frente, a costa da Berbéria, na fronteira do país dos mouros ou África ${ }^{26}$. Em 20 de fevereiro, estivemos na altura das Ilhas Canárias, passando-as mais de seis léguas pelo lado esquerdo; onde está a montanha mais alta do mundo, chamada o Pico do Tenerife, que se apresenta como uma nuvem escura. No mês de março, chegamos com o nosso navio e passageiros sãos e salvos na América, na costa do Brasil, desembarcando no Recife. Mas, pessoalmente, só estive quatro semanas nesse país, porque me mandaram com mais dezessete pessoas, no iate chamado Hasewind, para cruzar diante da costa de Angola na África ${ }^{27}$. Em efeito, lá tomamos uma caravela portuguesa com um emissário destinado a Portugal, o qual levamos ao Recife de Pernambuco.

\section{[Folha 7]}

Lá, cumpri meu serviço na terra e sobre o mar até ao ano de 1649. Em 19 de fevereiro, servindo no regimento de Sigemundt von Schkoppe, tenente-general das tropas da milícia terrestre e marítima, fui preso nos montes Guararapes quando fomos derrotados pelo mestre-de-campo português Francisco Barreto com sua gente e por outros mestres-de-campo com seus mulatos, negros, brasilianos e tapuias $^{28}$. Em 21 desse mês, mandaram-me preso ao Castelo do Pontal ${ }^{29} \mathrm{com} o$

\footnotetext{
${ }^{24}$ De acordo com H. D. Benjamins e J. F. Snelleman, existiam casas da Companhia das Índias Ocidentais nas cidades de Amsterdã, Delft, Dordrecht, Enkhuizen, Groningen, Hoorn, Midelburgo e Roterdã. Ver: Benjamins; Snelleman (1914-1917, p. 742-745).

${ }^{25} \mathrm{~A}$ embarcação Fortuna também era usualmente designada de "Fortuin" na documentação neerlandesa. "Genua”, "Leorn", “Neapolis", "Ciciliën” e "Malta” são as grafias utilizadas por Lorenz Simon para Gênova, Livorno, Nápoles, Sicília e Malta. Já Iráclio - ou Candia, em Latim, conforme a grafia posta por Lorenz no panfleto - fica em Creta.

${ }^{26} \mathrm{~A}$ costa da Berbéria - ou die Barbarische Cüste - corresponde à região costeira do Marrocos, Argélia, Tunísia e Líbia - o Magrebe.

27"late" também grafado na documentação neerlandesa como "Hazewint" - o Galgo.

${ }^{28}$ Simon grafou "Montes Guararapes" como "Gebirge von die Gorapis. Siegesmundus von Schuppen" - ou "Sigemundt von Schkoppe". Servia no Brasil desde 1630, retirando-se por um período com a chegada de Johan Maurits van Nassau-Siegen. Voltou em 1646, ocupando o posto de coronel e, em 1647, de tenentegeneral. Esteve no comando de tropas da WIC nas duas batalhas dos montes Guararapes. Francisco de Barette - ou Francisco Barreto de Menezes - serviu no Brasil entre 1638 e 1640, retornando a Portugal para participar da guerra de restauração. Em 1647, voltou para o Brasil com o posto de Mestre de Campo General do Estado do Brasil. Só assumiu seu posto em 1648, às vésperas da primeira batalha dos Guararapes, por ter sido feito prisioneiro. Acumulando o governo da Capitania de Pernambuco - e todas as outras do Norte -, ao qual foi nomeado em março de 1648, esteve à frente das tropas na segunda batalha dos Guararapes. Ver Mello (1979, p. 95-96). O termo "Brasilianen" empregado por Lorenz Simon, tem por origem a adoção, feita pelos neerlandeses, da "divisão entre os povos de língua Tupi ao longo da costa e os Tapuia, os "não-Tupi" do interior. Os primeiros foram denominados "Brasilianen" - brasileiros ou brasilianos -, vistos como "civilizados", em contraponto aos "bárbaros" tapuias. Ver Hulsman (2006, p. 41).

${ }^{29}$ O Castelo do Pontal - Castel Bondal - está localizado no Cabo de Santo de Agostinho, litoral sul de Pernambuco.
} 
capitão Mauritz ${ }^{30}$, o tenente Van Ancker ${ }^{31}$, um capitão-tenente de nome Carpentier Júnior $^{32}$, outro tenente de nome Josué ${ }^{33}$, um alferes da nobreza de Curlândia chamado Wieberg ${ }^{34}$, um capitão de navio ${ }^{35}$, um barbeiro do regimento do coronel Haultain $^{36}$, mais alguns suboficiais, e 150 soldados comuns. Com eles fiquei preso até 8 de agosto, quando, em nome de Deus, me meti ao mar em uma jangada, tal como nesta gravura se mostra como o Todo poderoso tão milagrosamente me tem salvo. Por tanto seja Ele eternamente louvado e agradecido para sempre, Amém.

\footnotetext{
${ }^{30}$ No original, "Capitain Mauritzz". Lorenz Simon provavelmente se referia ao capitão Mouris Louvaim, identificado como um dos integrantes do regimento do Coronel Van Elst que combateu em Guararapes Cap. Mouris - e também inserido na lista de mortos daquele regimento - Mauris Louvain. Uma vez que estava desaparecido, foi posto na lista de mortos. NL-HaNA_OWIC 1.05.01.01, inv. nr. 65, doc. 12, 19-02-1649 e inv. nr. 65, doc. 25, 19-02-1649.

${ }^{31}$ No original, "Lieutentant von Ancker". Na lista dos que "ficaram na Batalha nos Guararapes" (inde Battallie aende Guararapes sijn gebleven), figura o nome do tenente Corn. van. Ancker - ou Cornelis van den Ancker -, do regimento do coronel Guillaume de Haultain. NL-HaNA_OWIC 1.05.01.01, inv. nr. 65, doc. 24, 24-02-1649. O termo "ficar" pode parecer um eufemismo de "morrer", mas é mais apurado, uma vez que não se tinha uma contabilidade precisa dos mortos, desertores e prisioneiros da batalha. Prova disso é que Cornelis van den Ancker, assim como Mauris Louvaim, estavam entre os prisioneiros dos portugueses no Cabo de Santo Agostinho. Uma outra confirmação de que Van den Ancker estava vivo pode ser encontrada nas "Minutas dos cálculos das contas do pessoal militar que serviu pela WIC no Brasil", elaboradas pelos guarda-livros da WIC Gillis van Schendel e Johan van der Dussen e entregue aos Estados Gerais em 1655. Seu nome está posto entre a tropa recrutada pela Câmara de Amsterdã, junto com referências sobre seus salários acumulados nos anos de serviço no Brasil. NL-HaNA_SG 1.01.07, inv. nr. 12582.7, 1655.

${ }^{32}$ No original Jung Carpentier, que também pode ser traduzido como jovem Carpentier. São várias as pessoas da família Carpentier encontradas nos papéis da WIC. Vale destacar alguns nomes, como o mais conhecido deles, Servaes Carpentier (1599-1645). Servaes foi presidente do Conselho Político, médico e dono de engenho. Outros conhecidos membros da família são Gerard Carpentier, farmacéutico da WIC - irmão de Servaes -, e Roeland Carpentier (1603-?), que esteve envolvido na venda de pau-Brasil e também trabalhou em territórios dominados pela VOC. Ele retornou para os Países Baixos em 1688. Também há registro de um Carpentier de nome Johan (ou Johannes), que foi magistrado da cidade Maurícia e comissário das mercadorias. Um homônimo aparece em uma ata diária do Alto e Secreto Conselho do Brasil do dia 13 de novembro de 1645, na qualidade de comandante no Recife e tenente da companhia do capitão Jochen Deninger. Ele tinha sido tenente do major Pistor, conforme a referida ata, e outras dos dias 10 de maio de 1644 e 25 de abril de 1644. O tenente havia permanecido no Brasil após uma reforma feita no exército e fora recrutado na câmara de Amsterdã. Talvez esse Johan do exército seja filho do Johan que foi magistrado, ou o próprio magistrado. Um outro registro de Johan (Joannes) - o militar - está disposto nas "Minutas dos cálculos das contas do pessoal militar", de 1655, onde ele aparece com a patente de alferes (vaendrich) e com o nome Carpenter. Por fim, também foram encontrados um certo Willem Carpentier, que está registrado como militar proveniente da câmara da Zelândia nas "Minutas dos cálculos...", e o tenente Wouter Carpenter, registrado - em 24 de fevereiro de 1649 - como prisioneiro dos portugueses na lista de oficiais comissionados e não-comissionados do regimento do coronel Kerweer que "ficaram" em Guararapes. Wouter (ou Wolter Carpenter) também teve seu nome arrolado numa lista de 15 de abril de 1649. Eram os mortos em Guararapes da companhia do coronel Kerweer. Suspeita-se que Wouter seja o Carpentier mencionado por Lorenz Simon, haja vista a informação de que este fora feito prisioneiro em Guararapes. Ver Mello, 1978, p. 63, 155; Sellers, 1909, p. 26-30. NL-HaNA_OWIC 1.05.01.01, inv. nr. 49, doc. 138E, 26-10-1631; inv. nr. 63, docs. 28, 40; inv. nr. 65, doc. 24, 24-02-1649; inv. nr. 65, doc. 187, 15-04-1649; inv. nr. 70, DN 25-04-1644, DN 10-05-1644; inv. nr. 71, DN 13-11-1645; NL-HaNA SG 1.01.07, inv. nr. 12582.7, 1655.

${ }^{33}$ No original, "Josua”. Não foi encontrado qualquer tenente com nome Josué (Josua em alemão ou Jozua em neerlandês) ou variantes entre as listas de gente que lutou em Guararapes.

${ }^{34}$ No original, "Wieberg von Geschlechte". Também não foi encontrada qualquer informação sobre o alferes proveniente da atual região da Letônia.

${ }^{35}$ Conforme a lista da força designada para a expedição que lutou em Guararapes, de 19 de fevereiro, 250 marinheiros auxiliavam as tropas da expedição enviada a Guararapes. Eles estavam sob o comando do vice-almirante Matthiijs Gijllissen e de três capitães de navios. NL-HaNA_OWIC 1.05.01.01, inv. nr. 65, doc. 12 , 19-02-1649

${ }^{36}$ Guillaume de Haultain (ou Houthain) foi coronel de um dos regimentos envolvidos na refrega dos Guararapes. Era comum que as tropas levassem cirurgiões e barbeiros para as expedições militares, de maneira que eles atendessem os feridos e doentes. Alguns deles figuram nas listas de mortos mencionadas em notas anteriores.
} 


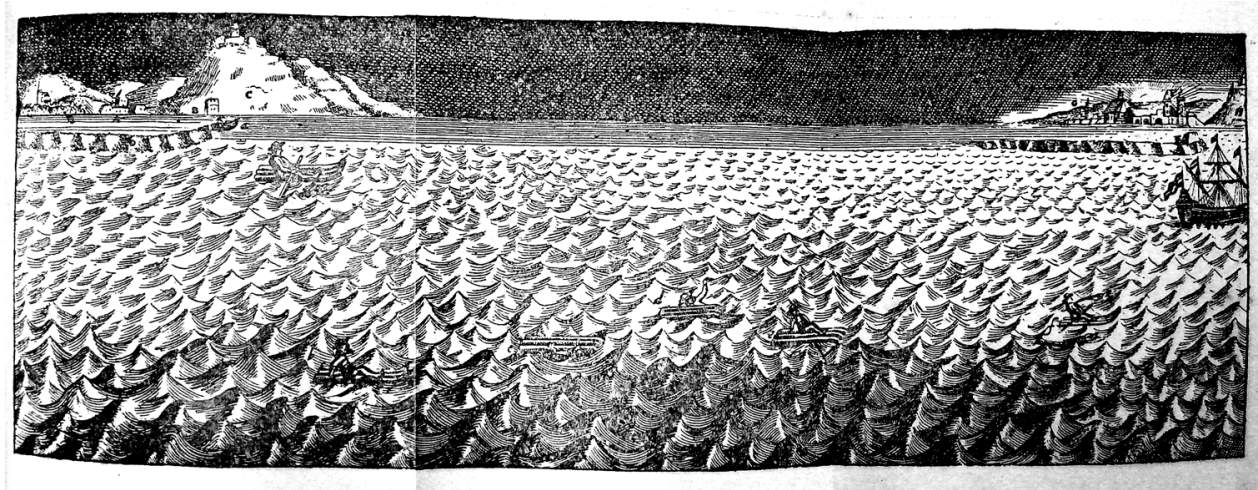

Uma história verdadeira que ocorreu com um soldado preso na América na costa do Brasil entre Pernambuco e o Cabo de Santo Agostinho, em 8 de agosto do ano de 1649. A. Pontal B. Forte Gijsselingh C. Cabo de Santo Agostinho D. Recife E. Castelo do Mar F. Castelo Friburgo G. Cidade do Recife H. Olinda

(a) Cheguei até aqui, na minha viagem, com êxito.

Com alegria, comecei a cantar: Assista-nos, Senhor Deus, e não nos abandone, Livre-nos dos pecados todos e assista-nos a morrer em paz.

\section{[Folha 8]}

(b) Aqui quis descansar de cansaço, mas fui logo pelo sono desenganado.

(c) Despertando-me, lembrei-me de Jesus.

(d) Oh, Senhor Jesus, socorra-me!

(e) Ao raiar do belo dia, não vi senão água e céu.

(f) Quando vi erguer-se o sol,

À terra logo voltei,

Lembrando-me em um instante

Que em frente em 700 léguas outra terra não havia

Que no país dos mouros ou África a costa de Angola.

(g) Quando aqui outra vez o caro sol de nós se retirou,

Consegui com trabalho um navio alcançar.

Chegado à terra, entrei de novo no serviço, cumprindo devidamente com ele junto ao Comissário da Artilharia até ao ano de 1654, quando o país todo do Brasil foi entregue em tratado aos portugueses. Como preso embarquei-me de novo com meu Comissário em um navio; junto com o Senhor Presidente Van Schonenburg ${ }^{37}$ e o Senhor Hendrik Haecxs ${ }^{38}$ de Amsterdã - ambos Altos Conselheiros da Companhia das Índias Ocidentais no Brasil - e com o tenente-general Sigemundt von Schkoppe. Em 10 de agosto, chegamos com nosso navio e gente à terra, em Zelândia, na cidade de Vlissingen.

${ }^{37}$ No original, Herrn President von Schonenburg. Wouter van Schonenburg (Schonenborch) foi, segundo Gonsalves de Mello, "ex-burgomestre da cidade de Groninga e membro dos Estados Gerais". Em 1645, foi comissionado presidente do Alto Governo instituído após a saída de Johan Maurits van Nassau-Siegen, Esteve no Brasil entre agosto de 1646 e abril de 1654. Ver Mello (2004, p. 499).

${ }^{38} \mathrm{No}$ original, Heirich Hachs. Hendrik Haecxs, conselheiro do Alto Governo do Brasil entre 1645 e 1654 , conforme visto anteriormente, viveu no Recife entre 1641 e 1644 e foi comissionado pela Câmara de Amsterdã conselheiro no Brasil, em 1645. Chegou ao Brasil, com o novo cargo, em agosto de 1646, retornando aos Países Baixos em setembro de 1647. Tinha por missão, delegada pelo governo da Companhia no Brasil, expor a situação da colônia e pedir reforços aos Estados Gerais. Fez novo retorno ao Brasil em março de 1648, onde ficou até 1654. Ver Mello (2004, p. 498). 


\section{Referências bibliográficas}

Articul-Brief. Beraemt over het Scheeps ende Crijgs Volck. Ten Dienste van de Geoctroyeerde WestIndische Compagnie in Brasyl, Guinea, etc. Groningen: Sas, 1640. Tradução livre.

ALDENBURGK, Johann Gregor. Relação da Conquista e perda da Cidade do Salvador pelos holandeses em 1624-1625, Vol. 1, Brasiliensia Documenta, 1961, traduzido por Alfredo de Carvalho e Edgard de Cerqueira Falcão.

AUGSPURGER, Johann Paul. Kurtze und warhaffte Beschreibung der See-Reisen von Amsterdam in Holland nacher Brasilien in America, und Angola in Africa. Vom 4. Novembris 1640, biss 10 Julii 1642. Schleusingen: Gedrukt bey Johann Michael Schalln, 1644.

BENJAMINS, Herman Daniël; SNELLEMAN, Joh. F. Encyclopaedie van Nederlandsch West-Indië (red.). Den Haag/Leiden: Martinus Nijhoff/E.J. Brill, 1914-1917.

BOXER, Charles Ralph. The Dutch Seaborne Empire, 1600-1800. London: Hutchinson, 1977.

CARVALHO, Alfredo. "A Viagem Brasílica de Lorenz Simon", Revista do Instituto Archeologico e Geographico Pernambucano, Recife, Tomo XI, 1904.

CARVALHO, Alfredo. "A Viagem de Nicolaus de Graaff”, Revista do Instituto Archeologico e Geographico Pernambucano. Vol. 13, n.71, Recife, 1908.

CARVALHO, Alfredo. Revista do Instituto Arqueológico, Histórico e Geográfico Pernambucano, n. 64, 2011.

EDWARDS, John; LYNCH, John. Historia de España. 4. Edad Moderna - El auge del imperio, 1474-1598. Barcelona: Crítica, 2005.

FRIEDRICHS, Christopher R. "The war and German society", in: Parker, Geoffrey (ed.), The Thirty Year's War, Second Edition. New York: Routledge, 2007.

GAASTRA, Femme S. The Dutch East India Company. Expansion and Decline. Zutphen: Walburg Pers, 2003.

GELDER, Roelof van. Het Oost-Indisch avontuur. Duitsers in dienst van de VOC (1600-1800), Nijmegen: SUN, 1997.

GROESEN, Michiel Van. "Officers of the West India Company, their networks, and their personal memories of Dutch Brazil”, in: Siegfried Huigen, Jan L. de Jong, Elmer Kolfin (eds.), Dutch Trading Companies as Knowledge Networks. Leiden: Brill, 2010.

HAECX, Hendrik. "Diário, 1645-1654", Anais da Biblioteca Nacional. Rio de Janeiro: Vol. 69, 1950, tradução do Frei Agostinho Keijzers.

HANSEN, Peter. "Memorial und Jurenal des Peter Hansen Haystrup", in: Frank Ibold, Jens Jäger, Detlev Kraack (eds.), Das Memorial und Jurenal des Peter Hansen Hajstrup (1624-1672). Neumünster: Wachholtz Verlag, 1995.

HEIJER, Henk den. "Diretores, Stadhouderes e Conselhos de Administração", in: Marianne Wiesebron (ed.), O Brasil em arquivos neerlandeses, vol. 2. Leiden: CNWS, 2005.

HEINTZE, Beatrix. Exploradores Alemães em Angola (1611-1945). Apropriações Etnográficas entre comércio de escravos, colonialismo e ciência. Frankfurt am Main: Frobenius Institut, 2010. HULSMAN, Lodewijk. "Índios do Brasil na República dos Países Baixos: As representações de Antônio Paraupaba para os Estados Gerais em 1654 e 1656”, Revista de História. São Paulo, n. 154, vol. 1, 2006.

IBOLD, Frank; JÄGER, Jens; KRAACK, Detlev. Das Memorial und Jurenal des Peter Hansen Hajstrup (1624-1672). Neumünster: Wachholtz Verlag, 1995

ISRAEL, Jonathan Irvine. The Dutch Republic: Its rise, greatness and fall, 1477-1806. Oxford: Clarendon Press-Oxford, 1995.

JACOBS, Jaap. "Soldaten van de Compagnie: het militair personeel van de West-Indische Compagnie in Nieuw-Nederland”, in: Maurits Ebben, Pieter Wagenaar (eds.), De cirkel doorbroken. Met nieuwe ideeën terug naar de bronnen. Opstellen over de Republiek. Leiden: Instituut voor Geschiedenis/Leidse Historische Studiën 10, 2006.

KRAACK, D. A. "Flensburg, an early modern centre of trade. The autobiographical writings of Peter Hansen Hajstrup (1624-1672)”, in: Juliette Roding, Lex Heerma van Voss (eds.), The North Sea and Culture (1550-1800). Hilversum: Verloren, 1996. p. 239-241.

LOHNSTEIN, M. J. De Militie van de Sociëteit c.q. Directie van Suriname in de achttiende eeuw. Velp: Scriptie Rijksuniversiteit Utrecht, 1984. 
LUCASSEN, Jan. "The Netherlands, the Dutch, and Long-Distance Migration, in the Late Sixteenth to Early Nineteenth Centuries", in: Nicholas Canny, Europeans on the Move. Studies on European Migration, 1500-1800. Oxford: Clarendon Press, 1994.

LUCASSEN, Jan. "The North Sea: a crossroad for migrants?", in: Juliette Roding, Lex Heerma van Voss (eds.). Oxford: Clarendon Press, 1994.

MAURO, Frédéric. "Merchant communities, 1530-1750", in: James D. Tracy (ed.), The Rise of Merchant Empires. Long-distance Trade in the Early Modern World 1350-1750, Cambridge, Cambridge University Press, 1990.

MELLO, José Antônio Gonsalves de. A rendição dos holandeses no Recife (1654). Recife: IPHAN/ MEC, 1979.

MELLO, José Antônio Gonsalves de. Fontes para a História do Brasil Holandês. Administração da Conquista. Vol. II. Recife: Companhia Editora de Pernambuco, 2004.

MELLO, José Antônio Gonsalves de. Tempo dos Flamengos. Influência da ocupação holandesa na vida e na cultura do norte do Brasil, 4a Edição. Rio de Janeiro: Topbooks, 2002.

MIRANDA, Bruno Romero Ferreira. Gente de guerra: Origem, cotidiano e resistência dos soldados do exército da Companhia das Índias Ocidentais no Brasil (1630-1654). Recife: Edufpe, 2014. NABER, Samuel Pierre l'Honoré. Reisebeschreibungen von Deutschen Beamten und Kriegsleuten im Dienst der Niederländischen West- und Ost-Indischen Kompagnien 1602-1797, Vol. I-XIII. Den Haag: Martinus Nijhoff, 1930/1932.

PARKER, Geoffrey. Atlas of the World, Desktop Edition. London: Times Books, 2008.

PARKER, Geoffrey. Compact History of the World. History brought to life (ed.). London: Times Books, 2008.

PARKER, Geoffrey. The military revolution. Military innovation and the rise of the West 15001800. Cambridge: Cambridge University Press, 1996.

PUDSEY, Cuthbert. Diário de uma Estada no Brasil, 1629-1640. Coleção Brasil Holandês, série VI, tomo III. Petrópolis: Editora Index, 2000.

RABB, Theodore K. "The Effects of the Thirty Years' War on the German Economy", The Journal of Modern History, Vol. 34, n. 1, 1962.

RICHSHOFFER, Ambrosius. Diário de um Soldado da Companhia das Índias Ocidentais, 16291632, Coleção Pernambucana Vol. XI. Recife: Governo do Estado de Pernambuco/Secretaria de Educação e Cultura, 1977, traduzido por Alfredo de Carvalho.

ROEPER, Vibeke; GELDER, Roelof van. In dienst van de Compagnie, Leven bij de VOC in honderd getuigenissen [1602-1799]. Amsterdam: Athenaeum/Polak \& Van Gennep, 2002.

SCHAMA, Simon. O desconforto da riqueza. A cultura holandesa na época de ouro. São Paulo: Companhia das Letras, 1992.

SELLERS, Edwin Jaquett. Genealogy of the De Carpentier family of Holland. Philadelphia: Allen Lane \& Scott, 1909.

SCHMIDT, Benjamin. Innocence abroad. The Dutch Imagination and the New World, 1570-1670. Cambridge: Cambridge University Press, 2001.

VRIES, Jan de. Ad van der Woude (eds.), The First Modern Economy. Success, failure, and perseverance of the Dutch economy, 1500-1815. Cambridge: Cambridge University Press, 1997.

WAGENER, Zacharias. O Thierbuch e a autobiografia de Zacharias Wagener, Coleção Brasil Holandês, Vol. II. Rio de Janeiro: Editora Index, 1997. 